\title{
Management of Cerebral Edema in Acute Liver Failure
}

\author{
Beverley Kok, MBBS $^{1}$ Constantine J. Karvellas, MD, SM ${ }^{1}$ \\ 1 Division of Gastroenterology (Liver Unit), Department of Critical \\ Care Medicine, University of Alberta, Edmonton, Canada \\ Semin Respir Crit Care Med 2017;38:821-829.

\begin{abstract}
Address for correspondence Constantine J. Karvellas, MD, SM, FRCPC, Division of Gastroenterology (Liver Unit), Department of Critical Care Medicine, University of Alberta, 1-40 Zeidler Ledcor Building, Edmonton, Alberta T6G-2 $\times 8$, Canada
\end{abstract} \\ (e-mail: dean.karvellas@ualberta.ca).
}

\author{
Abstract \\ Keywords \\ - acute liver failure \\ - intracranial \\ hypertension \\ - cerebral edema \\ - neuroprotection \\ - therapeutic \\ hypothermia
}

\begin{abstract}
Advances in medical care of the acute liver failure patient have led to a significant reduction in mortality related to the condition. Nevertheless, cerebral edema and ensuing brain herniation remains one of the top causes of demise in acute liver failure. Controversy remains regarding the utility of invasive intracranial pressure monitoring as well as usage of novel treatment modalities including therapeutic hypothermia. This review provides a brief summary into the pathophysiology and risk factors for developing cerebral edema in the context of acute liver failure; this review particularly provides a practical focus on general management of the patient with established cerebral edema as well as specific intracranial pressure-lowering strategies.
\end{abstract}

Acute liver failure (ALF) is a condition wherein a patient with a previously healthy liver rapidly deteriorates, resulting in jaundice, coagulopathy, and encephalopathy. This is usually accompanied by peripheral vasodilatation, features of the systemic inflammatory response syndrome, and ultimately multiorgan failure. ${ }^{1}$ The development of hepatic encephalopathy (HE) marks the transition from acute liver injury to ALF, and the timing of HE relative to the onset of jaundice plays a key role in defining prognosis. ${ }^{2}$ In the context of ALF, high-grade encephalopathy is commonly a manifestation of cerebral edema that may progress to cause death from cerebral herniation. ${ }^{3,4}$

There are approximately 2,000 cases per year of ALF in the United States, and approximately 1 in 6 cases per million annually throughout the world. ${ }^{5-7}$ Acetaminophen-induced ALF is the most common in developed nations, though viral infections are the predominant cause in developing countries. ${ }^{8}$

Previously, cerebral edema occurred in up to $80 \%$ of patients with ALF, contributing to the most common cause of death in ALF from herniation. ${ }^{3}$ Incidence of cerebral edema in ALF has, however, markedly declined over the past three decades. ${ }^{9} \mathrm{~A}$ review of more than 3,300 patients presenting to Kings College Hospital (the largest liver transplantation [LT] program in
Europe) over a 35-year period showed the proportion of ALF patients who developed intracranial hypertension had fallen from $76 \%$ during 1984-1988 to 20\% during 2004-2008 $(p<0.0001) .{ }^{9}$ Mortality from intracranial hypertension had also fallen from 95 to $55 \%$ ( $p<0.0001)$, likely a consequence of earlier illness recognition, improved intensive care, and use of emergency LT. ${ }^{9}$

Despite these improvements, brain herniation from cerebral edema remains one of the leading causes of mortality in ALF, following sepsis or sepsis-induced multiorgan failure. ${ }^{10}$ Once cerebral edema is present, it is associated with poor outcomes and complex management is required., ${ }^{9,11}$ This review will focus on the management of cerebral edema and intracranial hypertension in ALF.

\section{Pathophysiology}

Cerebral edema is a net increase in total brain water content. The rigid cranium protecting the brain limits its compliance, and small increases in fluid can cause significant rise in intracranial pressure (ICP), leading to decreased cerebral perfusion pressure (CPP) and capillary blood flow, causing ischemia. ${ }^{11}$ If sufficiently severe, cerebral edema culminates in tentorial brain herniation and death. ${ }^{11}$
Issue Theme Advancements in Neurocritical Care and Emergency Neurology; Guest Editors: David Y. Hwang, MD, FNCS, and David M. Greer, MD, MA, FCCM, FAHA, FNCS, FAAN, FANA
Copyright $\odot 2017$ by Thieme Medical Publishers, Inc., 333 Seventh Avenue, New York, NY 10001, USA.

Tel: +1(212) 584-4662.
DOI https://doi.org/ $10.1055 / \mathrm{s}-0037-1608772$. ISSN 1069-3424. 
The mechanisms behind the development of cerebral edema in ALF are complex and multifactorial, though cytotoxic edema (predominantly related to ammonia) is recognized to play a central role. ${ }^{12-14}$ Other mechanisms involved include vasogenic edema ${ }^{15,16}$ and impaired cerebral autoregulation. ${ }^{17,18}$

Ammonia predominantly originates from small bowel and is metabolized to urea by the liver through the urea cycle. In ALF, failure of the liver to detoxify ammonia leads to increases in serum ammonia. ${ }^{19}$ Ammonia diffuses across the blood-brain barrier easily. ${ }^{20}$ It is exclusively detoxified by glutamine synthetase contained within astrocytes into glutamine. ${ }^{20}$ Glutamine accumulation within astrocytes acts as an organic osmolyte drawing water and resulting in astrocytic swelling. ${ }^{19,21-23}$ In addition, glutamine may transport ammonia into mitochondria ("Trojan Horse hypothesis") inducing oxidative and nitrosative stresses that impair mitochondrial function and further potentiate astrocyte swelling. ${ }^{24-26}$ Mediators of systemic inflammatory response and proinflammatory cytokines may also act synergistically with ammonia to induce cerebral edema, though these pathways are less well characterized. ${ }^{27,28}$

To a much smaller extent, altered blood-brain barrier permeability may exacerbate cerebral edema through a vasogenic mechanism. ${ }^{29-31}$ Magnetic resonance imaging of patients with ALF demonstrating interstitial brain edema lends support to this theory. ${ }^{15,16}$

Impaired cerebral autoregulation and cerebral hyperemia have been reported in clinical and animal models, exacerbating raised ICP with ALF. ${ }^{18,32,33}$ Cerebral autoregulation usually serves to maintain a stable cerebral blood flow (CBF) to the brain commensurate with metabolic demands despite variations in mean arterial pressure (MAP). ${ }^{34}$ This mechanism is disrupted in ALF allowing inappropriate rises in CBF with increased MAP, or vice versa with hypotension. ${ }^{35,36}$

\section{Clinical Diagnosis of Cerebral Edema in ALF}

Early recognition of cerebral edema is important, as prolonged exposure may result in cerebral ischemia with permanent neurological disability and significant morbidity and mortality. ${ }^{37}$ The goals of treating cerebral edema are hence not only to prevent herniation but also to optimize neurological recovery.

ALF patients who are particularly at risk for developing substantial cerebral edema include those with a more rapid progression of liver injury to HE, such as those with hyperacute or acute presentations (i.e., acetaminophen), 2,4,19,38 those with high-grade HE (grade III/IV), ${ }^{2,39}$ high serum ammonia $(>150-200 \mu \mathrm{mol} / \mathrm{L}),{ }^{10,40}$ younger individuals (age $<35$ years), ${ }^{10}$ those with infection and/or systemic inflammatory response syndrome, ${ }^{27,28}$ those with high Sequential Organ Failure Assessment (SOFA) scores, ${ }^{41}$ and those requiring vasopressors or renal replacement therapy $(\text { RRT })^{10}(-$ Table 1$)$. The risk of cerebral edema increases to 25 to $35 \%$ with grade III HE and 65 to $75 \%$ or more in patients reaching grade IV HE. ${ }^{42}$

ALF patients should have frequent examinations (at least every 2 hours) concentrating on pupil size, coma grade,
Table 1 Factors associated with developing substantial cerebral edema

\begin{tabular}{|l|}
\hline Hyperacute presentations (e.g., acetaminophen) \\
\hline Younger individuals $(<35 \mathrm{y})$ \\
\hline High-grade hepatic encephalopathy \\
\hline Serum ammonia $>150 \mathrm{\mu mol} / \mathrm{L}$ \\
\hline Systemic inflammatory response syndrome \\
\hline Concurrent infection \\
\hline High Sequential Organ Failure Assessment score \\
\hline Requirement for vasopressors or renal replacement therapy \\
\hline
\end{tabular}

evidence of delirium, and deep tendon reflexes. The development of grade II or higher HE should result in transfer to a critical care area, ${ }^{43}$ with development of grade III HE usually necessitating intubation and ventilation. ${ }^{44}$ As cerebral edema may not always be associated with clinical signs, ${ }^{4,45}$ ammonia may also be useful in guiding preemptive management in this respect. ${ }^{40}$ Arterial ammonia $>150$ to $200 \mu \mathrm{mol} / \mathrm{L}$ predicts a greater likelihood of developing or dying from brain herniation. ${ }^{40,46}$ In a Kings College Hospital cohort, 55\% of patients with ammonia $>200 \mu \mathrm{mol} / \mathrm{L}$ developed intracranial hypertension. ${ }^{10}$

Development of raised ICP should be suspected with sudden-onset systemic hypertension, changes in pupillary reactivity (usually dilatation), ${ }^{47}$ and abnormal oculovestibular reflexes or decerebrate posturing, though these signs are neither specific nor sensitive for elevated ICP. ${ }^{45}$ Seizures and agitation are frequently present. While computed tomography is insensitive in detecting cerebral edema, ${ }^{48}$ its usage is worthwhile to rule out other intracranial pathology such as hemorrhage. ${ }^{48,49}$

\section{Monitoring: To Bolt or Not to Bolt?}

Invasive ICP monitoring remains the most accurate tool for diagnosis and management of cerebral edema, though its use is limited by a 1 to $10 \%$ risk of significant intracranial hemorrhage and the limited evidence proving clinical benefit. ${ }^{44,50-54}$ ICP in ALF may suddenly rise from normal to life-threatening levels within minutes, and in this situation continuous ICP monitoring allows rapid and specific management.

The United States ALF Study Group (ALFSG) ${ }^{55}$ as with several other groups ${ }^{56-58}$ recommend the placement of ICP monitors in patients with high-grade HE (grade III/IV). An approach by Kings College Hospital is to monitor ICP in patients with clinical signs or evidence of evolving cerebral edema. $^{1}$

Other indications for increased risk and hence invasive ICP monitoring may include ammonia $>150$ to $200 \mu \mathrm{mol} / \mathrm{L}$; listing for LT; meeting Kings College criteria for poor prognosis; the presence of multisystem organ failure, $\mathrm{HE}$ and hyponatremia, HE and seizures, HE and pupillary abnormalities, abnormal jugular venous oxygen saturations, and transcranial Doppler ultrasonography (TCD) indicating very high or very low $\mathrm{CBF}^{10,59-61}$ Clinical endpoints for 
ICP monitoring are not standardized, but most centers aim to achieve an ICP $<20$ to $25 \mathrm{~mm} \mathrm{Hg}$ and CPP $>50$ to $60 \mathrm{~mm}$ Hg. ${ }^{55,62,63}$

In a recent survey of 22 high-volume transplantation centers in 11 countries, ICP monitoring in ALF was employed in 12 centers, with the most common indications being papilledema and acute kidney injury. ${ }^{62}$ The overall proportion of patients with grade III HE and above who underwent ICP monitoring was low, even in centers that performed this procedure often. Among the centers that did utilize ICP monitoring, six centers reported using it in $<25 \%$ of the patients with high-grade $\mathrm{HE}$ and four centers performed monitoring in $>75 \%$ of patients with high-grade HE. Earlier surveys from the United States have similarly showed decreasing use of ICP monitoring. ${ }^{50}$ Use of fresh-frozen plasma, cryoprecipitate, and platelets prior to ICP monitor insertion may be required, ${ }^{43,62}$ though additional dynamic assessments of coagulation such as with thromboelastography may aid in the decision making in the correction of coagulopathy.

Such trends of decreased use of ICP monitoring may be a reflection of evidence to date failing to demonstrate a survival benefit. $^{52}$ In a large multicenter retrospective cohort study, Karvellas et $\mathrm{al}^{52}$ showed that raised ICP was present in $51 \%$ of those with ICP monitors, and patients with ICP monitoring received significantly more cerebral edema-directed therapies. Hemorrhagic complications leading to death were low (5\%), but there was no 21-day mortality benefit in acetaminophen-related ALF patients who received monitoring, and a worse prognosis in the non-acetaminophen group. These results are similar to earlier retrospective studies that did not demonstrate improved survival with ICP monitoring, although complication rates were low. ${ }^{50,54,57,64}$ Jugular venous oxygen saturation monitoring in addition to ICP monitoring is recommended by some groups; this provides an indication of cerebral metabolism and oxygenation, which become abnormal with the loss of CBF autoregulation. ${ }^{60,65}$

TCD offers a noninvasive alternative to obtaining indirect evidence regarding ICP and $\mathrm{CBF}^{66}$ though there are limited data to guide clinical use specifically in ALF. ${ }^{67,68}$ It may be useful in patients with severe coagulopathy at high risk for bleeding complications, and has an added advantage over standard invasive monitoring in its ability to estimate $\mathrm{CBF}^{69}$ Reduced blood flow on TCD can indicate cerebral edema, although it may be inaccurate for mild-to-moderate ICP elevations. ${ }^{69}$ Alternative noninvasive monitoring techniques such as continuous neurophysiological monitoring, nearinfrared spectroscopy, optic nerve sonography, and pupillometry are not validated in ALF. ${ }^{70}$

\section{General Measures: Prophylaxis}

It is recommended that patients with ALF and impending cerebral edema be managed in an intensive care unit (ICU); the U.S. Acute Liver Failure Study Group (ALFSG) guidelines propose that an ICU setting is indicated with progression to grade II HE. ${ }^{55}$ Management in the ICU aims to provide organ support with continuous monitoring of central hemodynamic parameters, but, in addition, should encompass

Table 2 General measures in patients with cerebral edema

Intubation and ventilation in high-grade hepatic

encephalopathy

Sedation with propofol

Minimal environmental stimulation

Head in neutral position; head of bed elevated to 30 degrees

neuroprotective measures designed to prevent the development or ameliorate the severity of raised ICP ( - Table 2 ). ${ }^{1,59}$

Progression to grade III/IV HE should prompt sedation with propofol, intubation, and ventilation. ${ }^{55,71}$ In a recent multicenter survey, grade II HE was the most common grade of HE prompting transfer to an ICU or high dependency bed, and most centers intubated patients at grade III HE. ${ }^{62}$

Propofol has anticonvulsant properties and may reduce ICP by reducing CBF. ${ }^{49,60,72,73}$ Seizures should be treated, but prophylactic phenytoin has not been shown to reduce the incidence of seizures nor mortality in ALF. ${ }^{74,75}$

Positive end-expiratory pressure (PEEP) may also increase ICP when mean airway pressures are increased and should be used carefully, ${ }^{76}$ though PEEP $<15$ has not been shown to affect ICP significantly. ${ }^{70}$ Procedures provoking high intrathoracic pressures (such as endotracheal suctioning) may also result in venous outflow obstruction and should be minimized. ${ }^{55,77}$ Environmental stimulation should be minimized. ${ }^{44,55}$

Due to impaired cerebral autoregulation, systemic hypotension may reduce CPP and induce brain ischemia, though hypertension may also increase ICP. ${ }^{78}$ A reasonable goal is to aim for a MAP of $>75 \mathrm{~mm} \mathrm{Hg} .^{79}$ Central venous pressure should be maintained at $<20 \mathrm{~mm} \mathrm{Hg}$ to avoid impeding cerebral venous return. ${ }^{80}$ In patients with persistent hypotension despite volume repletion, norepinephrine is the preferred vasopressor, with or without adjunctive vasopressin or vasopressin analogs. 81

If cerebral edema is confirmed, the head should be in neutral position and the head of the bed elevated to 30 degrees $^{82}$ to maximize cerebrospinal fluid and venous drainage. ${ }^{76,83}$ Some with markedly compromised CPP may not tolerate elevation of the bed, and so it is always necessary to make individual assessments. ${ }^{45}$

Use of lactulose may cause bowel distention and ileus and should be limited. ${ }^{70}$ Hypoglycemia should be treated, but large-volume infusions of hypotonic fluids which may result in hyponatremia and worsen cerebral swelling should be avoided. $^{1}$

Currently, the use of prophylactic antibiotics and antifungals in patients with ALF is not generally recommended, though periodic surveillance is advocated. ${ }^{84}$

\section{Intracranial Pressure-Lowering Measures}

Once cerebral edema has developed, the main strategies for improving it can be classified into those aimed at reducing brain volume and those reducing CBF ( - Table 3$).{ }^{60}$ 
Table 3 Intracranial pressure-lowering measures

\begin{tabular}{|c|c|}
\hline Reducing brain volume & $\begin{array}{l}\text { Reducing cerebral } \\
\text { blood flow }\end{array}$ \\
\hline $\begin{array}{l}\text { Continuous renal replacement } \\
\text { therapy }^{98} \\
\text { Hypertonic saline } \\
\text { Mannitol }^{92}\end{array}$ & $\begin{array}{l}\text { Propofol sedation }{ }^{102} \\
\text { Forced } \\
\text { hyperventilation }^{108}, \text { a } \\
\text { Moderate hypothermia }^{a}\end{array}$ \\
\hline
\end{tabular}

${ }^{\mathrm{a} O n l y}$ in refractory situations.

\section{Reducing Brain Volume}

Recently published clinical practice guidelines from the European Association of the Study of Liver (EASL) for the management of ALF have recommended the use of either hypertonic saline (HTS) or mannitol as the first-line therapy in established cerebral edema, in addition to optimal sedation. $^{43}$

HTS and mannitol both ameliorate cerebral edema predominantly via an osmotic dehydration effect, promoting a fluid shift from the brain to the intravascular compartment, reversing cerebral edema and $\mathrm{ICP}^{85,86}$

\section{Hypertonic Saline}

The efficacy of HTS in lowering ICP is similar to mannitol ${ }^{87,88}$ and may result in a more prolonged reduction to ICP, though this difference may be restricted to the first bolus. ${ }^{88}$ In the only prospective randomized controlled clinical trial involving HTS in the management of ALF, HTS was shown to be beneficial in reducing the incidence of intracranial hypertension, and decreased ICP relative to controls. ${ }^{53}$ Some guidelines hence advocate the prophylactic use of HTS in those at highest risk of developing $\mathrm{HE},{ }^{55}$ though the latest 2017 EASL guidelines recommend a clamping of serum sodium at 140 to $145 \mathrm{mmol} / \mathrm{L}$ and treatment with a bolus of $200 \mathrm{~mL}, 2.7 \%$ or $20 \mathrm{~mL}, 30 \%$ HTS only when cerebral edema has developed. ${ }^{43}$

The risks of HTS in ALF relate to its potential to induce brain dehydration due to osmotic shifts, or severe hypernatremia. ${ }^{86,89}$ It is recommended that serum sodium be maintained at $<160 \mathrm{mmol} / \mathrm{L}$, though this threshold was inspired by studies using mannitol. ${ }^{86,90}$ Hyperosmolality may be less of an issue if hemofiltration is ongoing and euvolemia can be maintained. Another consideration is rapid correction of hyponatremia that may result in central and extrapontine myelinolysis. ${ }^{91}$ The U.S. ALFSG guidelines recommend that although hyponatremia of short duration is not a contraindication to administering HTS, the rate of correction should be inversely proportional to the duration of hyponatremia to minimize this risk of osmotic demyelination. ${ }^{55}$

\section{Mannitol}

The use of mannitol is widely accepted as a first-line therapy for intracranial hypertension in several centers. ${ }^{55,62}$ Prophylactic use of mannitol has not been studied and is not recommended. ${ }^{55}$ The efficacy of mannitol in ALF-induced intracranial hypertension was confirmed by a controlled trial demonstrating that mannitol administration $(1 \mathrm{~g} / \mathrm{kg}$ ) in those with intracranial hypertension significantly reduced ICP, though there was a lack of effect in those with renal failure $^{92}$ or severe intracranial hypertension (>60 $\left.\mathrm{mm} \mathrm{Hg}\right){ }^{93}$ Though a range of doses have been used in patients with ALF $(0.25-1.0 \mathrm{~g} / \mathrm{kg}){ }^{36,92}$ the EASL 2017 guidelines recommend a bolus of $50 \mathrm{~mL}, 20 \%$ to be administered over 20 minutes. ${ }^{43}$ The U.S. ALFSG guidelines recommend that mannitol therapy may be repeated once or twice, so long as serum osmolality remains $<320 \mathrm{mOsm} / \mathrm{L}^{55}$

Mannitol will transiently expand circulating blood volume, and concurrent ultrafiltration may be required to prevent rise in central venous pressure and to maintain euvolemia. ${ }^{55}$ Once administered, serum osmolality should be assessed regularly, though it has been shown that serum osmolality correlates poorly with mannitol concentrations, and a normal osmolar gap may be a more accurate measure of adequate mannitol clearance prior to administration of subsequent doses. ${ }^{94}$ A maximal serum osmolality of $<320 \mathrm{mOsm} / \mathrm{L}$ is generally quoted, though this was derived from limited evidence to prevent renal tubular damage, and breaching this target may not be harmful provided the patient is not volume depleted. ${ }^{95,96}$ Repeated use of mannitol may be especially associated with serious adverse effects such as intravascular volume depletion, rebound ICP elevation, and renal failure from mannitol accumulation. ${ }^{95,97}$

\section{Renal Replacement Therapy}

Slack et al demonstrated that early initiation of RRT with continuous veno-venous hemofiltration is an effective method of decreasing the level of circulating ammonia, with a clear correlation between creatinine clearance and ammonia clearance. ${ }^{98}$ Continuous rather than intermittent dialysis is generally used to achieve greater metabolic and hemodynamic stability. ${ }^{99}$ Though initiation of RRT primarily for hyperammonemia rather than acute kidney injury has not been studied in a randomized controlled fashion, the latest EASL guidelines recommend the early consideration of continuous RRT for those in ALF with persistent hyperammonemia and/or progressive HE, control of hyponatremia and metabolic abnormalities, fluid balance, and potentially temperature control. $^{43}$

\section{Reducing Cerebral Blood Flow}

In the context of ALF, disrupted cerebral autoregulation to ICP leads to cerebral hyperemia. ${ }^{100}$ Reduction of CBF may be mitigated by processes that either reduce brain metabolism or result in cerebral vasoconstriction.

\section{Pharmacologic Coma}

\section{Propofol}

Propofol decreases the cerebral metabolic rate and oxygen demands and hence reduces $\mathrm{CBF}^{101}$ It has been shown to control ICP in ALF patients. ${ }^{102}$ Propofol has beneficial anticonvulsant properties and permits a faster return to wakefulness, as its pharmacokinetics are not influenced by liver failure; ${ }^{103}$ hence, its use has largely replaced barbiturateinduced coma. Propofol sedation is usually utilized early in 
the course of ALF to facilitate intubation and ventilation once a patient develops high-grade HE, and hence offers potential protection from the development of intracranial hypertension.

\section{Barbiturates}

Barbiturate agents such as thiopental or pentobarbital reduce the cerebral metabolic rate and may be utilized to decrease ICP. ${ }^{104,105}$ Due to their side-effect profile, however, they are generally considered a short-term salvage therapy. ${ }^{62}$ Although previously recommended in refractory cases, ${ }^{57,104,106}$ rescue therapy with barbiturates has now been replaced by alternative strategies in many liver units. ${ }^{107}$ Potential adverse effects with barbiturate coma include loss of neurological exam, risk of infection, cardiac depression, and significant systemic hypotension. ${ }^{104}$

\section{Hyperventilation}

Forced hyperventilation induces hypocapnia and precapillary vasoconstriction and decreases CBF and ICP. ${ }^{108}$ Hyperventilation has also been shown to restore impaired cerebral autoregulation in ALF, though this effect may be short-lived. ${ }^{108}$ Hyperventilation carries a serious risk of provoking cerebral ischemia, and hence it should only be used in situations of cerebral hyperemia (which may be monitored by measuring jugular bulb saturations). ${ }^{109,110}$ The U.S. ALFSG recommends that spontaneous hyperventilation need not be treated, ${ }^{55}$ and targeting a low-normal $\mathrm{PaCO}_{2}$ (4-4.5 kPa) may be adopted instead. ${ }^{109}$ The utility of forced hyperventilation is in emergency rescue therapy of patients with evidence of diencephalic herniation. ${ }^{55}$ If employed, it should not be used for sustained periods. ${ }^{1,111}$ Some recommend that hyperventilation be stopped as soon as cerebral edema is controlled by other means. ${ }^{107}$ EASL 2017 guidelines recommend a short period of hyperventilation in resistant scenarios to reduce arterial $\mathrm{PaCO}_{2}$ to 25 to $30 \mathrm{~mm} \mathrm{Hg} .43$

\section{Moderate/Therapeutic Hypothermia}

The protective effect of hypothermia has been attributed to a reduction in the cerebral metabolic rate and brain energy demands. Hypothermia also protects neurons by maintaining the integrity of the lipoprotein membrane and decreasing enzymatic reactions that lead to cell damage or death. ${ }^{112}$ In ALF, further protective mechanisms of moderate hypothermia $(\mathrm{MH})$ include: (1) normalization of $\mathrm{CBF} ;{ }^{17,113}(2)$ reduction of arterial ammonia concentrations by slowing down protein catabolism, ${ }^{112,114}$ which together decrease delivery of ammonia to the brain; (3) reduced uptake of ammonia by the brain; ${ }^{115}$ (4) attenuating pathways that occur downstream of ammonia exposure within the brain, resulting in decreased lactate and glutamate accumulation and decreased cytokine production. ${ }^{116-118}$ In practice, clinical studies in ALF have achieved $\mathrm{MH}$ through the use of cooling blankets with targeted temperature measurements based on either superficial or core body temperatures. $^{115,119}$

Jalan et $\mathrm{al}^{35}$ demonstrated that in patients with ALF who fulfilled poor prognosis criteria with raised ICP refractory to mannitol and ultrafiltration, $\mathrm{MH}$ to 32 to $33^{\circ} \mathrm{C}$ core temperature resulted in rapid control of ICP, reduction in $\mathrm{CBF}$, increase in CPP, and reduction in arterial ammonia and cerebral uptake of ammonia. Subsequent studies by the same group demonstrated good outcomes and safety of using $\mathrm{MH}$ as a bridge to and during LT in ALF patients with refractory intracranial hypertension who would not otherwise have been considered suitable candidates. ${ }^{17,115}$

Clinical studies to date have, however, not demonstrated a beneficial impact on the prevention of intracranial hypertension with $\mathrm{MH}$. Karvellas et al in a retrospective cohort study investigated the impact of $\mathrm{MH}$ on the prevention of elevated ICP and transplant-free survival in ALF patients with grade IIIIV HE deemed high risk for developing intracranial hypertension. ${ }^{120}$ No differences in 21-day overall or transplant-free survival were found, though $\mathrm{MH}$ appeared to be associated with improved survival in young patients ( $<25$ years) with acetaminophen-ALF. The authors concluded that the results of their study could not conclusively confirm or refute the utility of $\mathrm{MH}$ for the prevention of intracranial hypertension in ALF patients. ${ }^{120}$ In the only multicenter randomized controlled trial regarding $\mathrm{MH}$ in ALF, Bernal et al investigated the prophylactic role of $\mathrm{MH}$ in ALF patients at high risk of cerebral edema. ${ }^{119}$ In their cohort of 43 patients, hypothermia at $34^{\circ} \mathrm{C}$ was administered for 72 hours and did not confer a benefit above $36^{\circ} \mathrm{C}$ in prevention. The trial was terminated early due to futility and an observed trend toward worsened ICP in those who received $\mathrm{MH}$.

Adverse event rates appear to relate closely to the minimum temperatures induced. ${ }^{121,122}$ Increased occurrence of sepsis has been observed in those cooled below $33^{\circ} \mathrm{C},{ }^{120}$ though arrhythmias have also been reported. ${ }^{119,120}$ Other reported concerns with $\mathrm{MH}$, such as worsening of coagulopathy ${ }^{123}$ or reduced hepatic regeneration, ${ }^{124}$ have not been observed in the ALF clinical trials so far. Risks associated with rewarming have, however, not been specifically addressed in the published literature so far. Although rewarming after LT appeared to be safe, ${ }^{35,115}$ a high death rate was observed to occur during or immediately following rewarming due to rapid rebound of ICP. ${ }^{35,119}$ Due to the possibility of rebound ICP, invasive ICP monitoring should probably form a necessary requirement as part of $\mathrm{MH}$ therapy, though there is currently a lack of evidence to support this.

Presently, $\mathrm{MH}$ remains a recommended treatment option, but only in those with refractory ICP elevation. ${ }^{43}$ There is no evidence to support an optimal temperature or duration of $\mathrm{MH}$. In the absence of refractory ICP elevation, a pragmatic approach to temperature management is to avoid fever and maintain a core body temperature of 35 to $36^{\circ} \mathrm{C}^{1}$

\section{Indomethacin}

Indomethacin acts by inducing cerebral vasoconstriction through multiple mechanisms. ${ }^{125,126}$ Though shown to be effective in reducing ICP in refractory intracranial hypertension, ${ }^{127}$ its use should only be in the context of hyperemic $\mathrm{CBF}^{128}$ to be accompanied by concurrent jugular venous bulb saturations monitoring ${ }^{127,128}$ due to risk of compromising 
CBF. It is currently indicated only if ICP remains elevated despite mannitol or HTS. ${ }^{43}$

\section{Others}

Plasmapheresis/Artificial Liver Support

Larsen et al investigated the effects of high-volume plasmapheresis in 12 patients with ALF ( 11 of who had grade IV HE) and reported a significant improvement in grade of $\mathrm{HE}$ and median CPP, although CBF was increased and ICP remained unchanged. ${ }^{129}$ These results showing improvement in cerebral hemodynamics were not replicated in a subsequent prospective randomized controlled trial looking at ALF patients (with minimum of grade II HE), although the authors report that the latter study was not sufficiently powered to observe any potential benefit. ${ }^{130}$

Use of albumin dialysis with the Molecular Adsorbent Recirculating System (MARS) in a randomized controlled trial of ALF patients did not demonstrate any significant improvement to ammonia levels or HE, though its effect on modulating cerebral edema is uncertain as none of the patients in the study had received ICP monitoring. ${ }^{131}$

\section{Total Hepatectomy}

Therapeutic hepatectomy in patients awaiting LT may be of value in desperate situations. ${ }^{39,132}$ The proposed hypothesis for this measure is that removing "necrotic liver" may reduce liver-derived proinflammatory cytokines, reducing nitric oxide and CBF as well as improving mediator-induced cytotoxic injury. ${ }^{133,134}$

\section{Conclusion}

Several options exist for the treatment of established intracranial hypertension in ALF and may successfully bridge patients to definitive treatment of transplantation. The utility of invasive ICP monitoring remains controversial, but is indicated in high-risk cases and could be supported by additional noninvasive monitoring (such as reverse jugular saturations and TCD). Further work is needed in delineating futility of treatment in patients with cerebral edema who are not suitable for $\mathrm{LT}$.

\section{Conflict of Interest}

All authors have no personal or funding conflict of interest.

\section{Financial Support}

None.

\section{References}

1 Bernal W, Wendon J. Acute liver failure. N Engl J Med 2013;369 (26):2525-2534

2 O'Grady JG, Alexander GJ, Hayllar KM, Williams R. Early indicators of prognosis in fulminant hepatic failure. Gastroenterology 1989;97(02):439-445

3 Blei AT. Medical therapy of brain edema in fulminant hepatic failure. Hepatology 2000;32(03):666-669
4 O'Grady JG, Schalm SW, Williams R. Acute liver failure: redefining the syndromes. Lancet 1993;342(8866):273-275

5 Bower WA, Johns M, Margolis HS, Williams IT, Bell BP. Population-based surveillance for acute liver failure. Am J Gastroenterol 2007;102(11):2459-2463

6 Escorsell A, Mas A, de la Mata M; Spanish Group for the Study of Acute Liver Failure. Acute liver failure in Spain: analysis of 267 cases. Liver Transpl 2007;13(10):1389-1395

7 Wei G, Bergquist A, Broomé U, et al. Acute liver failure in Sweden: etiology and outcome. J Intern Med 2007;262(03):393-401

8 Acharya SK, Batra Y, Hazari S, Choudhury V, Panda SK, Dattagupta S. Etiopathogenesis of acute hepatic failure: Eastern versus Western countries. J Gastroenterol Hepatol 2002;17(Suppl 3): S268-S273

9 Bernal W, Hyyrylainen A, Gera A, et al. Lessons from look-back in acute liver failure? A single centre experience of 3300 patients. J Hepatol 2013;59(01):74-80

10 Bernal W, Hall C, Karvellas CJ, Auzinger G, Sizer E, Wendon J. Arterial ammonia and clinical risk factors for encephalopathy and intracranial hypertension in acute liver failure. Hepatology 2007;46(06):1844-1852

11 Larsen FS, Wendon J. Brain edema in liver failure: basic physiologic principles and management. Liver Transpl 2002;8(11): 983-989

12 Saksena S, Rai V, Saraswat VA, et al. Cerebral diffusion tensor imaging and in vivo proton magnetic resonance spectroscopy in patients with fulminant hepatic failure. J Gastroenterol Hepatol 2008;23(7, Pt 2):e111-e119

13 Norenberg MD. A light and electron microscopic study of experimental portal-systemic (ammonia) encephalopathy. Progression and reversal of the disorder. Lab Invest 1977;36(06): 618-627

14 Jalan R, Olde Damink SW, Hayes PC, Deutz NE, Lee A. Pathogenesis of intracranial hypertension in acute liver failure: inflammation, ammonia and cerebral blood flow. J Hepatol 2004;41 (04):613-620

15 Kale RA, Gupta RK, Saraswat VA, et al. Demonstration of interstitial cerebral edema with diffusion tensor MR imaging in type $C$ hepatic encephalopathy. Hepatology 2006;43(04):698-706

16 Rai V, Nath K, Saraswat VA, Purwar A, Rathore RK, Gupta RK. Measurement of cytotoxic and interstitial components of cerebral edema in acute hepatic failure by diffusion tensor imaging. J Magn Reson Imaging 2008;28(02):334-341

17 Jalan R, Olde Damink SW, Deutz NE, Hayes PC, Lee A. Restoration of cerebral blood flow autoregulation and reactivity to carbon dioxide in acute liver failure by moderate hypothermia. Hepatology 2001;34(01):50-54

18 Larsen FS, Ejlersen E, Hansen BA, Knudsen GM, Tygstrup N, Secher NH. Functional loss of cerebral blood flow autoregulation in patients with fulminant hepatic failure. J Hepatol 1995;23 (02):212-217

19 Blei AT. The pathophysiology of brain edema in acute liver failure. Neurochem Int 2005;47(1-2):71-77

20 Cooper AJ, Plum F. Biochemistry and physiology of brain ammonia. Physiol Rev 1987;67(02):440-519

21 Martinez-Hernandez A, Bell KP, Norenberg MD. Glutamine synthetase: glial localization in brain. Science 1977;195 (4284):1356-1358

22 Häussinger D, Kircheis G, Fischer R, Schliess F, vom Dahl S. Hepatic encephalopathy in chronic liver disease: a clinical manifestation of astrocyte swelling and low-grade cerebral edema? J Hepatol 2000;32(06):1035-1038

23 Butterworth RF. Hepatic encephalopathy and brain edema in acute hepatic failure: does glutamate play a role? Hepatology 1997;25(04):1032-1034

24 Rama Rao KV, Norenberg MD. Glutamine in the pathogenesis of hepatic encephalopathy: the Trojan horse hypothesis revisited. Neurochem Res 2014;39(03):593-598 
25 Norenberg MD. Oxidative and nitrosative stress in ammonia neurotoxicity. Hepatology 2003;37(02):245-248

26 Albrecht J, Norenberg MD. Glutamine: a Trojan horse in ammonia neurotoxicity. Hepatology 2006;44(04):788-794

27 Rolando N, Wade J, Davalos M, Wendon J, Philpott-Howard J, Williams R. The systemic inflammatory response syndrome in acute liver failure. Hepatology 2000;32(4, Pt 1):734-739

28 Vaquero J, Polson J, Chung C, et al. Infection and the progression of hepatic encephalopathy in acute liver failure. Gastroenterology 2003;125(03):755-764

29 Kato M, Hughes RD, Keays RT, Williams R. Electron microscopic study of brain capillaries in cerebral edema from fulminant hepatic failure. Hepatology 1992;15(06):1060-1066

30 Chastre A, Bélanger M, Nguyen BN, Butterworth RF. Lipopolysaccharide precipitates hepatic encephalopathy and increases blood-brain barrier permeability in mice with acute liver failure. Liver Int 2014;34(03):353-361

31 Nguyen JH, Yamamoto S, Steers J, et al. Matrix metalloproteinase-9 contributes to brain extravasation and edema in fulminant hepatic failure mice. J Hepatol 2006;44(06):1105-1114

32 Strauss G, Hansen BA, Kirkegaard P, Rasmussen A, Hjortrup A, Larsen FS. Liver function, cerebral blood flow autoregulation, and hepatic encephalopathy in fulminant hepatic failure. Hepatology 1997;25(04):837-839

33 Durham S, Yonas H, Aggarwal S, Darby J, Kramer D. Regional cerebral blood flow and $\mathrm{CO} 2$ reactivity in fulminant hepatic failure. J Cereb Blood Flow Metab 1995;15(02):329-335

34 Czosnyka M, Brady K, Reinhard M, Smielewski P, Steiner LA. Monitoring of cerebrovascular autoregulation: facts, myths, and missing links. Neurocrit Care 2009;10(03):373-386

35 Jalan R, O Damink SW, Deutz NE, Lee A, Hayes PC. Moderate hypothermia for uncontrolled intracranial hypertension in acute liver failure. Lancet 1999;354(9185):1164-1168

36 Wendon JA, Harrison PM, Keays R, Williams R. Cerebral blood flow and metabolism in fulminant liver failure. Hepatology 1994;19(06):1407-1413

37 Ware AJ, D’Agostino AN, Combes B. Cerebral edema: a major complication of massive hepatic necrosis. Gastroenterology 1971;61(06):877-884

38 Bernal W, Auzinger G, Dhawan A, Wendon J. Acute liver failure. Lancet 2010;376(9736):190-201

39 Blei AT, Larsen FS. Pathophysiology of cerebral edema in fulminant hepatic failure. J Hepatol 1999;31(04):771-776

40 Clemmesen JO, Larsen FS, Kondrup J, Hansen BA, Ott P. Cerebral herniation in patients with acute liver failure is correlated with arterial ammonia concentration. Hepatology 1999;29(03): 648-653

41 Kitzberger R, Funk GC, Holzinger U, et al. Severity of organ failure is an independent predictor of intracranial hypertension in acute liver failure. Clin Gastroenterol Hepatol 2009;7(09):1000-1006

42 Muñoz SJ, Moritz MJ, Bell R, Northrup B, Martin P, Radomski J. Factors associated with severe intracranial hypertension in candidates for emergency liver transplantation. Transplantation 1993;55(05):1071-1074

43 Wendon J, Cordoba J, Dhawan A, et al; European Association for the Study of the Liver. Electronic address: easloffice@easloffice. eu; Clinical practice guidelines panel; Panel members; EASL Governing Board representative. EASL Clinical Practical Guidelines on the management of acute (fulminant) liver failure. J Hepatol 2017;66(05):1047-1081

44 Bernal W, Auzinger G, Sizer E, Wendon J. Intensive care management of acute liver failure. Semin Liver Dis 2008;28(02):188-200

45 Mohsenin V. Assessment and management of cerebral edema and intracranial hypertension in acute liver failure. J Crit Care 2013;28(05):783-791

46 Kumar R, Shalimar, Sharma H, et al. Persistent hyperammonemia is associated with complications and poor outcomes in patients with acute liver failure. Clin Gastroenterol Hepatol 2012;10(08): 925-931

47 Yan S, Tu Z, Lu W, et al. Clinical utility of an automated pupillometer for assessing and monitoring recipients of liver transplantation. Liver Transpl 2009;15(12):1718-1727

48 Muñoz SJ, Robinson M, Northrup B, et al. Elevated intracranial pressure and computed tomography of the brain in fulminant hepatocellular failure. Hepatology 1991;13(02):209-212

49 Wijdicks EF, Plevak DJ, Rakela J, Wiesner RH. Clinical and radiologic features of cerebral edema in fulminant hepatic failure. Mayo Clin Proc 1995;70(02):119-124

50 Vaquero J, Fontana RJ, Larson AM, et al. Complications and use of intracranial pressure monitoring in patients with acute liver failure and severe encephalopathy. Liver Transpl 2005;11(12): 1581-1589

51 Blei AT, Olafsson S, Webster S, Levy R. Complications of intracranial pressure monitoring in fulminant hepatic failure. Lancet 1993;341(8838):157-158

52 Karvellas CJ, Fix OK, Battenhouse H, Durkalski V, Sanders C, Lee WM; U S Acute Liver Failure Study Group. Outcomes and complications of intracranial pressure monitoring in acute liver failure: a retrospective cohort study. Crit Care Med 2014;42(05): 1157-1167

53 Murphy N, Auzinger G, Bernel W, Wendon J. The effect of hypertonic sodium chloride on intracranial pressure in patients with acute liver failure. Hepatology 2004;39(02):464-470

54 Keays RT, Alexander GJ, Williams R. The safety and value of extradural intracranial pressure monitors in fulminant hepatic failure. J Hepatol 1993;18(02):205-209

55 Lee WM, Stravitz RT, Larson AM. Introduction to the revised American Association for the Study of Liver Diseases Position Paper on acute liver failure 2011. Hepatology 2012;55(03): 965-967

56 Raschke RA, Curry SC, Rempe S, et al. Results of a protocol for the management of patients with fulminant liver failure. Crit Care Med 2008;36(08):2244-2248

57 Lidofsky SD, Bass NM, Prager MC, et al. Intracranial pressure monitoring and liver transplantation for fulminant hepatic failure. Hepatology 1992;16(01):1-7

58 Detry O, Arkadopoulos N, Ting P, et al. Intracranial pressure during liver transplantation for fulminant hepatic failure. Transplantation 1999;67(05):767-770

59 Stravitz RT, Kramer AH, Davern T, et al; Acute Liver Failure Study Group. Intensive care of patients with acute liver failure: recommendations of the U.S. Acute Liver Failure Study Group. Crit Care Med 2007;35(11):2498-2508

60 Shawcross DL, Wendon JA. The neurological manifestations of acute liver failure. Neurochem Int 2012;60(07):662-671

61 Scott TR, Kronsten VT, Hughes RD, Shawcross DL. Pathophysiology of cerebral oedema in acute liver failure. World J Gastroenterol 2013;19(48):9240-9255

62 Rabinowich L, Wendon J, Bernal W, Shibolet O. Clinical management of acute liver failure: results of an international multicenter survey. World J Gastroenterol 2016;22(33):7595-7603

63 Polson J, Lee WM; American Association for the Study of Liver Disease. AASLD position paper: the management of acute liver failure. Hepatology 2005;41(05):1179-1197

64 Daas M, Plevak DJ, Wijdicks EF, et al. Acute liver failure: results of a 5-year clinical protocol. Liver Transpl Surg 1995;1(04):210-219

65 Larsen FS, Ejlersen E, Clemmesen JO, Kirkegaard P, Hansen BA. Preservation of cerebral oxidative metabolism in fulminant hepatic failure: an autoregulation study. Liver Transpl Surg 1996;2(05):348-353

66 Aggarwal S, Brooks DM, Kang Y, Linden PK, Patzer JF II. Noninvasive monitoring of cerebral perfusion pressure in patients with acute liver failure using transcranial Doppler ultrasonography. Liver Transpl 2008;14(07):1048-1057 
67 Abdo A, Pérez-Bernal J, Hinojosa R, et al. Cerebral hemodynamics patterns by transcranial Doppler in patients with acute liver failure. Transplant Proc 2015;47(09):2647-2649

68 Kawakami M, Koda M, Murawaki Y. Cerebral pulsatility index by transcranial Doppler sonography predicts the prognosis of patients with fulminant hepatic failure. Clin Imaging 2010;34(05): 327-331

69 Sidi A, Mahla ME. Noninvasive monitoring of cerebral perfusion by transcranial Doppler during fulminant hepatic failure and liver transplantation. Anesth Analg 1995;80(01):194-200

70 Kandiah PA, Kumar G. Hepatic encephalopathy-the old and the new. Crit Care Clin 2016;32(03):311-329

71 Singanayagam A, Bernal W. Update on acute liver failure. Curr Opin Crit Care 2015;21(02):134-141

72 Ravussin P, Guinard JP, Ralley F, Thorin D. Effect of propofol on cerebrospinal fluid pressure and cerebral perfusion pressure in patients undergoing craniotomy. Anaesthesia 1988;43(Suppl):37-41

73 Hartung HJ. [Modification of intracranial pressure by propofol (Disoprivan). Initial results]. Anaesthesist 1987;36(02):66-68

74 Ellis AJ, Wendon JA, Williams R. Subclinical seizure activity and prophylactic phenytoin infusion in acute liver failure: a controlled clinical trial. Hepatology 2000;32(03):536-541

75 Bhatia V, Batra Y, Acharya SK. Prophylactic phenytoin does not improve cerebral edema or survival in acute liver failure-a controlled clinical trial. J Hepatol 2004;41(01):89-96

76 Bingaman WE, Frank JI. Malignant cerebral edema and intracranial hypertension. Neurol Clin 1995;13(03):479-509

77 Citerio G, Vascotto E, Villa F, Celotti S, Pesenti A. Induced abdominal compartment syndrome increases intracranial pressure in neurotrauma patients: a prospective study. Crit Care Med 2001;29(07):1466-1471

78 Ede RJ, Gimson AE, Bihari D, Williams R. Controlled hyperventilation in the prevention of cerebral oedema in fulminant hepatic failure. J Hepatol 1986;2(01):43-51

79 Cardoso FS, Marcelino P, Bagulho L, Karvellas CJ. Acute liver failure: an up-to-date approach. J Crit Care 2017;39:25-30

80 Scheuermann K, Thiel C, Thiel K, et al. Correlation of the intracranial pressure to the central venous pressure in the late phase of acute liver failure in a porcine model. Acta Neurochir Suppl (Wien) 2012;114:387-391

81 Eefsen M, Dethloff T, Frederiksen HJ, Hauerberg J, Hansen BA, Larsen FS. Comparison of terlipressin and noradrenalin on cerebral perfusion, intracranial pressure and cerebral extracellular concentrations of lactate and pyruvate in patients with acute liver failure in need of inotropic support. J Hepatol 2007;47 (03):381-386

82 Durward OJ, Amacher AL, Del Maestro RF, Sibbald WJ. Cerebral and cardiovascular responses to changes in head elevation in patients with intracranial hypertension. J Neurosurg 1983;59 (06):938-944

83 Davenport A, Will EJ, Davison AM. Effect of posture on intracranial pressure and cerebral perfusion pressure in patients with fulminant hepatic and renal failure after acetaminophen selfpoisoning. Crit Care Med 1990;18(03):286-289

84 Karvellas CJ, Cavazos J, Battenhouse H, et al; US Acute Liver Failure Study Group. Effects of antimicrobial prophylaxis and blood stream infections in patients with acute liver failure: a retrospective cohort study. Clin Gastroenterol Hepatol 2014;12 (11):1942-9.e1

85 Winkler SR, Munoz-Ruiz L. Mechanism of action of mannitol. Surg Neurol 1995;43(01):59

86 Suarez JI. Hypertonic saline for cerebral edema and elevated intracranial pressure. Cleve Clin J Med 2004;71(Suppl 1):S9-S13

87 Harutjunyan L, Holz C, Rieger A, Menzel M, Grond S, Soukup J. Efficiency of 7.2\% hypertonic saline hydroxyethyl starch 200/0.5 versus mannitol $15 \%$ in the treatment of increased intracranial pressure in neurosurgical patients - a randomized clinical trial [ISRCTN62699180]. Crit Care 2005;9(05):R530-R540
88 Battison C, Andrews PJ, Graham C, Petty T. Randomized, controlled trial on the effect of a $20 \%$ mannitol solution and a $7.5 \%$ saline/6\% dextran solution on increased intracranial pressure after brain injury. Crit Care Med 2005;33(01):196-202, discussion 257-258

89 Qureshi AI, Suarez JI. Use of hypertonic saline solutions in treatment of cerebral edema and intracranial hypertension. Crit Care Med 2000;28(09):3301-3313

90 The Brain Trauma Foundation. The Brain Trauma Foundation. The American Association of Neurological Surgeons. The Joint Section on Neurotrauma and Critical Care. Guidelines for cerebral perfusion pressure. J Neurotrauma 2000;17(6-7):507-511

91 Martin RJ. Central pontine and extrapontine myelinolysis: the osmotic demyelination syndromes. J Neurol Neurosurg Psychiatry 2004;75(Suppl 3):iii22-iii28

92 Canalese J, Gimson AE, Davis C, Mellon PJ, Davis M, Williams R. Controlled trial of dexamethasone and mannitol for the cerebral oedema of fulminant hepatic failure. Gut 1982;23(07): 625-629

93 Hanid MA, Davies M, Mellon PJ, et al. Clinical monitoring of intracranial pressure in fulminant hepatic failure. Gut 1980; 21(10):866-869

94 García-Morales EJ, Cariappa R, Parvin CA, Scott MG, Diringer MN. Osmole gap in neurologic-neurosurgical intensive care unit: its normal value, calculation, and relationship with mannitol serum concentrations. Crit Care Med 2004;32(04):986-991

95 Diringer MN, Zazulia AR. Osmotic therapy: fact and fiction. Neurocrit Care 2004;1(02):219-233

96 Rabinstein AA. Treatment of cerebral edema. Neurologist 2006; 12(02):59-73

97 Wakai A, Roberts I, Schierhout G. Mannitol for acute traumatic brain injury. Cochrane Database Syst Rev 2007;(01):CD001049

98 Slack AJ, Auzinger G, Willars C, et al. Ammonia clearance with haemofiltration in adults with liver disease. Liver Int 2014;34 (01):42-48

99 Davenport A. Continuous renal replacement therapies in patients with liver disease. Semin Dial 2009;22(02):169-172

100 Larsen FS, Strauss G, Møller K, Hansen BA. Regional cerebral blood flow autoregulation in patients with fulminant hepatic failure. Liver Transpl 2000;6(06):795-800

101 Oshima T, Karasawa F, Satoh T. Effects of propofol on cerebral blood flow and the metabolic rate of oxygen in humans. Acta Anaesthesiol Scand 2002;46(07):831-835

102 Wijdicks EF, Nyberg SL. Propofol to control intracranial pressure in fulminant hepatic failure. Transplant Proc 2002;34(04): $1220-1222$

103 Veroli P, O'Kelly B, Bertrand F, Trouvin JH, Farinotti R, Ecoffey C. Extrahepatic metabolism of propofol in man during the anhepatic phase of orthotopic liver transplantation. Br J Anaesth 1992;68(02):183-186

104 Forbes A, Alexander GJ, O'Grady JG, et al. Thiopental infusion in the treatment of intracranial hypertension complicating fulminant hepatic failure. Hepatology 1989;10(03):306-310

105 Raghavan M, Marik PE. Therapy of intracranial hypertension in patients with fulminant hepatic failure. Neurocrit Care 2006;4 (02):179-189

106 Polderman KH. Application of therapeutic hypothermia in the intensive care unit. Opportunities and pitfalls of a promising treatment modality-Part 2: Practical aspects and side effects. Intensive Care Med 2004;30(05):757-769

107 Rabinstein AA. Treatment of brain edema in acute liver failure. Curr Treat Options Neurol 2010;12(02):129-141

108 Strauss G, Hansen BA, Knudsen GM, Larsen FS. Hyperventilation restores cerebral blood flow autoregulation in patients with acute liver failure. J Hepatol 1998;28(02):199-203

109 Wendon J, Lee W. Encephalopathy and cerebral edema in the setting of acute liver failure: pathogenesis and management. Neurocrit Care 2008;9(01):97-102 
110 Ellis A, Wendon J. Circulatory, respiratory, cerebral, and renal derangements in acute liver failure: pathophysiology and management. Semin Liver Dis 1996;16(04):379-388

111 Jalan R. Acute liver failure: current management and future prospects. J Hepatol 2005;42(1, Suppl):S115-S123

112 Vaquero J, Rose C, Butterworth RF. Keeping cool in acute liver failure: rationale for the use of mild hypothermia. J Hepatol 2005;43(06):1067-1077

113 Sinclair HL, Andrews PJ. Bench-to-bedside review: hypothermia in traumatic brain injury. Crit Care 2010;14(01):204

114 Vaquero J, Bélanger M, James L, et al. Mild hypothermia attenuates liver injury and improves survival in mice with acetaminophen toxicity. Gastroenterology 2007;132(01):372-383

115 Jalan R, Olde Damink SW, Deutz NE, Hayes PC, Lee A. Moderate hypothermia in patients with acute liver failure and uncontrolled intracranial hypertension. Gastroenterology 2004;127 (05):1338-1346

116 Córdoba J, Crespin J, Gottstein J, Blei AT. Mild hypothermia modifies ammonia-induced brain edema in rats after portacaval anastomosis. Gastroenterology 1999;116(03):686-693

117 Rose C, Michalak A, Pannunzio M, Chatauret N, Rambaldi A, Butterworth RF. Mild hypothermia delays the onset of coma and prevents brain edema and extracellular brain glutamate accumulation in rats with acute liver failure. Hepatology 2000;31 (04):872-877

118 Chatauret N, Zwingmann C, Rose C, Leibfritz D, Butterworth RF. Effects of hypothermia on brain glucose metabolism in acute liver failure: a $\mathrm{H} / \mathrm{C}$-nuclear magnetic resonance study. Gastroenterology 2003;125(03):815-824

119 Bernal W, Murphy N, Brown S, et al. A multicentre randomized controlled trial of moderate hypothermia to prevent intracranial hypertension in acute liver failure. J Hepatol 2016;65(02):273-279

120 Karvellas CJ, Todd Stravitz R, Battenhouse H, Lee WM, Schilsky ML; US Acute Liver Failure Study Group. Therapeutic hypothermia in acute liver failure: a multicenter retrospective cohort analysis. Liver Transpl 2015;21(01):4-12

121 Geurts M, Macleod MR, Kollmar R, Kremer PH, van der Worp HB. Therapeutic hypothermia and the risk of infection: a systematic review and meta-analysis. Crit Care Med 2014;42(02):231-242

122 Stravitz RT, Larsen FS. Therapeutic hypothermia for acute liver failure. Crit Care Med 2009;37(7, Suppl):S258-S264

123 Forman KR, Wong E, Gallagher M, McCarter R, Luban NL, Massaro AN. Effect of temperature on thromboelastography and implica- tions for clinical use in newborns undergoing therapeutic hypothermia. Pediatr Res 2014;75(05):663-669

124 Munoz SJ. Hypothermia may impair hepatic regeneration in acute liver failure. Gastroenterology 2005;128(04):1143-1144, author reply $1144-1145$

125 Jensen K, Ohrström J, Cold GE, Astrup J. The effects of indomethacin on intracranial pressure, cerebral blood flow and cerebral metabolism in patients with severe head injury and intracranial hypertension. Acta Neurochir (Wien) 1991;108(3-4):116121

126 Chung C, Gottstein J, Blei AT. Indomethacin prevents the development of experimental ammonia-induced brain edema in rats after portacaval anastomosis. Hepatology 2001;34(02): 249-254

127 Tofteng F, Larsen FS. The effect of indomethacin on intracranial pressure, cerebral perfusion and extracellular lactate and glutamate concentrations in patients with fulminant hepatic failure. J Cereb Blood Flow Metab 2004;24(07):798-804

128 Clemmesen JO, Hansen BA, Larsen FS. Indomethacin normalizes intracranial pressure in acute liver failure: a twenty-three-yearold woman treated with indomethacin. Hepatology 1997;26 (06):1423-1425

129 Larsen FS, Hansen BA, Ejlersen E, et al. Cerebral blood flow, oxygen metabolism and transcranial Doppler sonography during high-volume plasmapheresis in fulminant hepatic failure. Eur J Gastroenterol Hepatol 1996;8(03):261-265

130 Larsen FS, Schmidt LE, Bernsmeier C, et al. High-volume plasma exchange in patients with acute liver failure: an open randomised controlled trial. J Hepatol 2016;64(01):69-78

131 Saliba F, Camus C, Durand F, et al. Albumin dialysis with a noncell artificial liver support device in patients with acute liver failure: a randomized, controlled trial. Ann Intern Med 2013;159(08): 522-531

132 Bismuth H, Samuel D, Castaing D, Williams R, Pereira SP. Liver transplantation in Europe for patients with acute liver failure. Semin Liver Dis 1996;16(04):415-425

133 Jalan R, Pollok A, Shah SH, Madhavan K, Simpson KJ. Liver derived pro-inflammatory cytokines may be important in producing intracranial hypertension in acute liver failure. J Hepatol 2002; 37(04):536-538

134 Ringe B, Lübbe N, Kuse E, Frei U, Pichlmayr R. Total hepatectomy and liver transplantation as two-stage procedure. Ann Surg 1993;218(01):3-9 